\title{
Robotic Process Automation: A New Enabler for Digital Transformation and Operational Excellence
}

\author{
Shaoyang $\mathrm{Bu}^{1}$, Uk A Jeong ${ }^{2}$, Joon $\mathrm{Koh}^{1}$ \\ ${ }^{1}$ Chonnam National University, Gwangju, Korea \\ ${ }^{2}$ IBM Data \& Al, Automation, IBM Korea, Seoul, Korea
}

Objectives: Due to the explosive growth of the internet, mobile applications, machine learning, and new information technologies, new management methods that do not require face-to-face contact are spreading rapidly. Innovative approaches to process automation are needed in the era of the coronavirus disease 2019 (COVID-19) pandemic, and firms are actively adopting and implementing solutions such as robotic process automation (RPA) to increase their operational excellence. The objective of this study is to address state-of-the-art use cases of RPA by IBM Korea to determine key factors related to successful RPA implementation.

Methods: Multiple case study methods and triangulation of findings were used. This study examined several cases in which RPA was implemented and proposed an analytical framework for RPA.

Results: This article described IBM's RPA usage strategies to accelerate business process management and examined four cases of RPA implementation by client firms of IBM in South Korea. This case study found that IBM's RPA solutions positively affected the client firms' performance, suggesting that solutions like RPA could be essential for firms' survival due to the benefits of process automation.

Conclusions: Solutions using RPA can both reduce labor costs and improve the operational excellence of firms' internal processes. Due to the COVID-19 pandemic, process automation is increasingly essential. Practical issues such as change management and shadow work caused by process automation are discussed.

Key Words: Process Automation, Shadow Work, Operational Excellence, Case Study, IBM Korea

\section{Introduction}

In recent years, artificial intelligence (AI) and the Fourth Industrial Revolution have prompted explosive growth in various industrial automation processes using robotics instead of hu-

Received: Nov 5, 2021 Revised: Nov 29, 2021 Accepted: Dec 4, 2021

Corresponding author: Joon Koh

School of Business Administration, Chonnam National University, 77 Yongbong-Ro, Buk-Gu, Gwangju 61186, Korea

Tel: +82-62-530-1459, E-mail: kjoon@chonnam.ac.kr

This is an Open Access article distributed under the terms of the Creative Commons Attribution Non-Commercial License (http://creativecommons.org/licenses/ by-nc/4.0/) which permits unrestricted non-commercial use, distribution, and reproduction in any medium, provided the original work is properly cited.

Copyright ( $\odot 2022$ Korean Association for Business Communication. man labor in brick-and-mortar, pure-click, and hybrid industries, as well as service-oriented industries. The rapid adoption of information and communication technologies (ICT) to reduce in-person contact during the coronavirus disease 2019 (COVID-19) pandemic has accelerated the transition at many firms from human-based labor to robot-based automation for routine procedures and smart enterprises. For example, at call centers, most customers initially interact with automatic response services (ARS) rather than employees directly. Chatbots (Heo \& Lee, 2018) are often used as substitutes for contact center employees. As a result, many firms plan to implement e-transformation from the old style to the new style of work in their internal processes.

In modern business environments, firms require higher 
numbers of data workers to undertake new business launches and implement process innovation (PI). For example, firms need machine learning $(\mathrm{ML})$ engineers, hybrid $\mathrm{ML}$ engineers with strong/deep domain knowledge, system engineers skilled in both robotic process automation (RPA) and domain knowledge, and new business creators who understand that business spin-off methods with transformational leadership are essential for the art of automation. In other words, RPA has a long track record of organizational development for the digital transformation of firms. The objective of this study is to conduct a case study and explore critical factors related to the successful implementation of RPA.

The new way of doing business using RPA is influencing decision-makers at firms in various industries. To meet business needs, major information technology (IT) solution giants such as IBM, AWS, LG, CNS, and McKinsey \& Company are emphasizing the effects of PI enablers/software such as RPA for improving firm performance. IBM Korea, as a large IT vendor, has emphasized the advantages of RPA during the COVID-19 pandemic as a novel solution and has recommended RPA products for implementing smart business process management (BPM) solutions to client firms. As a result, many client firms have gained both quantitative and qualitative benefits from using RPA solutions provided by IBM.

This study attempts to conceptualize RPA as a new enabler of PI and e-transformation. It also outlines how such solutions can affect business performance in both business-to-business (B2B) and business-to-consumer (B2C) contexts. Using the case report as an analytical framework, we describe several cases in which RPA was successfully adopted and implemented. However, some obstacles and impediments must be overcome before the successful e-transformation of firms. For example, firms may need to develop or recruit relevant data specialists/workers to achieve the degree of organizational efficiency and operational excellence promised by RPA. For this, we employ the concept of shadow work in digital business environments and potential issues such as required changes in management to implement RPA solutions. We also discuss academic and practical implications, lessons from this case analysis, study limitations, and future research directions.

\section{Robotic Process Automation}

RPA is a method of performing day-to-day business processes by automating the way people interact, either through user interfaces with multiple applications or through analytics and simple rules to make decisions (Deloitte, 2017). RPA is defined as a preconfigured software instance that uses business rules and predefined activity choreography to complete the autonomous execution of a combination of processes, activities, transactions, and tasks in 1 or more unrelated software systems to deliver services with human exception management (IEEE Corporate Advisory Group, 2017). RPA can automate tasks that employees must routinely perform to optimize workflows, and RPA tools are designed to reduce the burden of repetitive, simple tasks on employees (Aguirre \& Rodriguez, 2017). RPA is therefore akin to traditional automation measures such as the implementation of assembly-line technologies (Moffitt, Rozario, \& Vasarhelyi, 2018). Thus, instead of implementing new systems or reengineering existing systems, RPA automates parts of the process by replacing existing manual processes with automated ones at the presentation layer only (IRPA, 2016). As such, by replacing human workers with digital workers, RPA can optimize business processes and increase efficiency (Figure 1).

RPA is increasingly becoming an everyday element of organizations' business operations. It can bring immediate value to core business processes through the automation of processes such as employee payroll, new employee recruitment and onboarding, financial management, invoice processing, inventory management, report creation, data migration, and more. In addition, RPA has a wide range of applications in various industries such as healthcare and pharmaceuticals, financial services, outsourcing, retail, telecommunications, energy and utilities, real estate, and fast-moving consumer goods (Madakam, Holmukhe, \& Jaiswal, 2019). For example, the RPA can be used as an automated overlay of existing IT systems to perform combined audit tasks or conduct analysis across multiple unrelated software systems (Huang \& Vasarhelyi, 2019). In September 2015, Naver launched a cardbot, which proposes various selection scenarios based on the most frequently asked questions and categorizes them according to buyers' needs (Heo \& Lee, 2018). In addition, smart spreadsheets that convert complex paperwork into digital forms in a corporate environment are now used by financial institutions for paperless banking services, tablet banking, and remote contracting systems (Chang \& Park, 2018). Recruitment integration solutions in the field of AI for recruiting can analyze data from large groups of applicants in a short time using document reviews, personality tests, interview screening, and judgment recommendations (Son, Lee, \& Chang, 2019).

Firms are leveraging automation to increase productivity and gain a competitive advantage. Since RPA can be used for a wide range of information systems (IS) and applications with varying degrees of capability and compatibility, it is an attractive solution in many cases. The implementation of RPA can result in many benefits related to various enterprises. Since RPA can altogether eliminate some tasks and automate others, overall 
As-IS : Human Labor
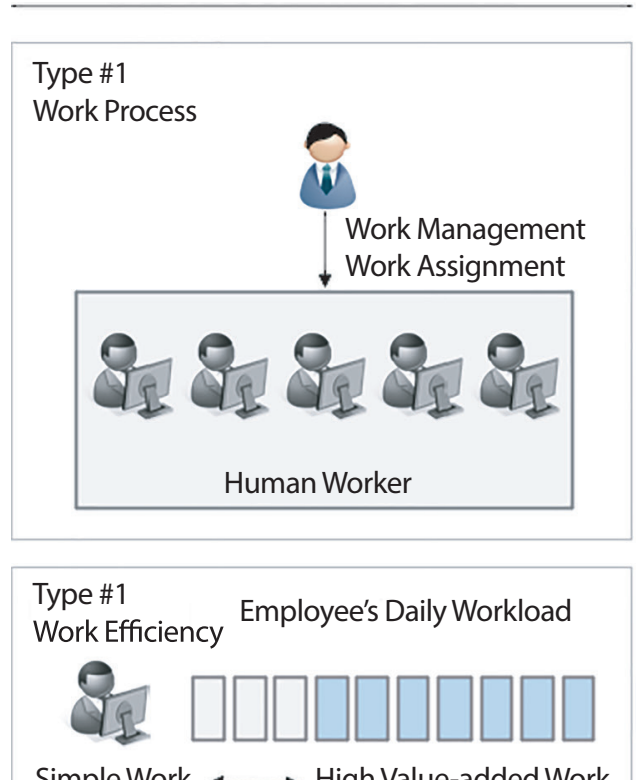

TO-BE : Digital Labor

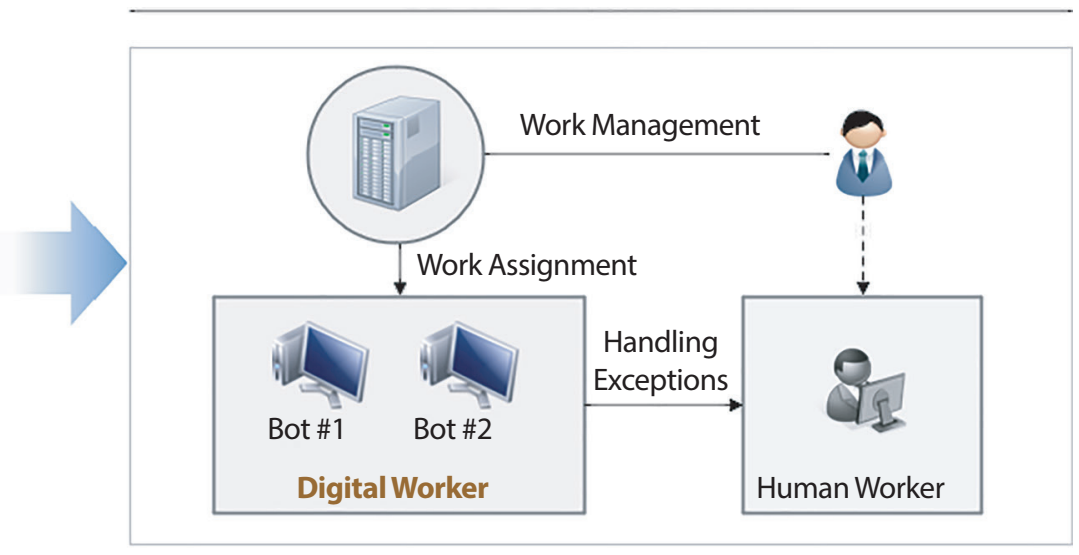

Employee's Daily Workload

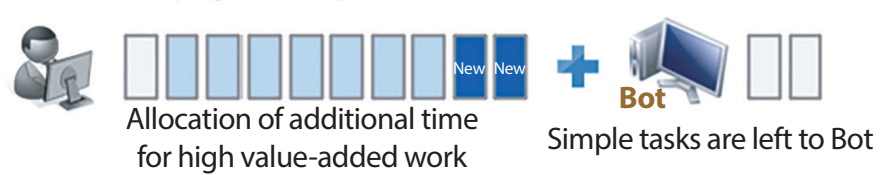

Figure 1. The expected effects of RPA implementation. RPA, robotic process automation.

work time can be substantially reduced, enabling organizations to significantly reduce the overall size of teams dedicated to certain tasks. The use of automation enables more accounts to be monitored and leads to the proactive identification of more potentially fraudulent accounts, allowing organizations to take action to prevent losses. In addition, the use of automation for manual tasks such as data entry reduces errors and improves the overall data quality of client accounts. The use of bots to run specific processes also led to the creation of records associated with these tasks, allowing managers to quickly understand processes and stay informed about operations at any time.

When evaluating the benefits of investing in RPA, its costs must also be considered. To implement RPA for existing processes, organizations require corresponding software that supports automation. However, the exact software required depends on the characteristics of the processes being automated. In addition to the costs of new software, organizations should also consider the internal development (hidden) costs for frontend software used to upload documents, manage queues, and quickly interact across applications. Depending on the task, specialized programming knowledge is not necessarily required to develop a software robot; however, one must have a basic understanding of the functions of the IS. While fairly low IT complexity makes RPA an easy-to-use tool for various people and functions in businesses, strong and deep process knowledge is a determinant in software bot development (Willcocks, Lacity, \& Craig, 2015). This requires companies to conduct additional
RPA-related talent development or training programs to ensure that their employees have the ability to identify, implement, and maintain RPA solutions. Thus, firms to implement RPA should consider both the operational improvement expected by RPA in the side of its benefits and hardware/software investment/ implementation costs including change management.

\section{Case Analysis}

\section{Methods}

Based on the theories of mental accounting (Park \& Koh, 2018; Thaler, 1999) and IS implementation (Kwon \& Zmud, 1987), we employ an analytical framework for this case study. According to the mental accounting theory (Park \& Koh, 2018), firm decision-makers can decide whether they should adopt RPA by calculating the costs and its benefits. Once a firm decides to adopt and implement RPA, it should consider change management and the results of implementation based on the study of Kwon and Zmud (1987). Figure 2 combines these theories and depicts a framework for the case analyses in this study concerning the adoption and implementation of RPA.

\section{Case Description}

Using the above framework, this article describes the RPA usage strategies used by IBM to accelerate BPM and described several instances of RPA implementation in B2C and B2B contexts in South Korea. 


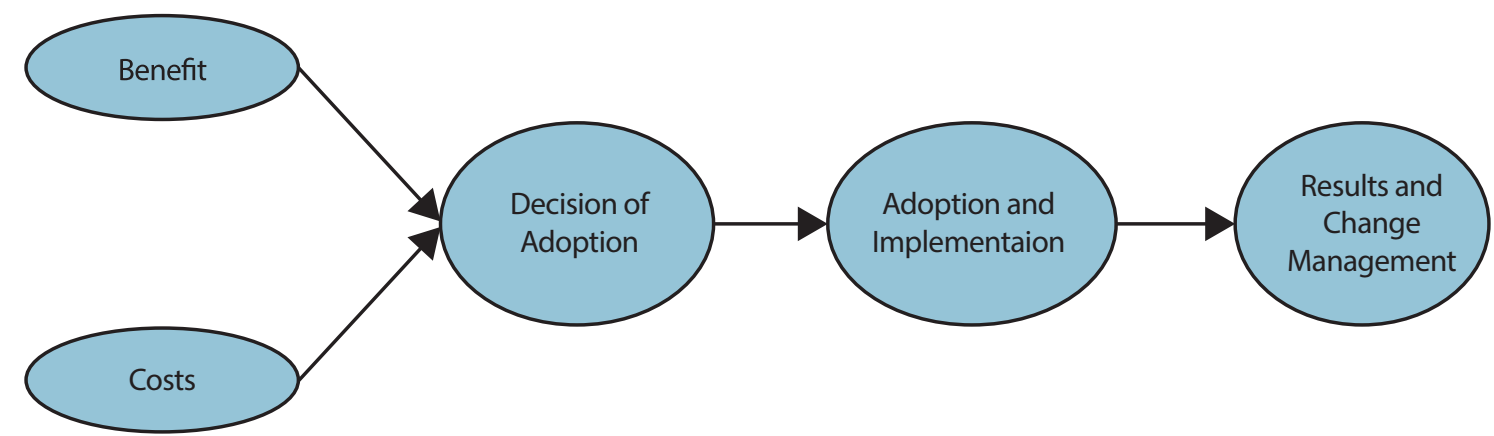

Figure 2. Framework for case analysis.

\section{Case A}

Company A is a TV home shopping brand affiliated with a conglomerate in Korea having TV shopping, internet shopping, mobile shopping, and T-commerce divisions. In addition to AIbased services, the company has also developed mobile content.

The company lacked inspection personnel, with only $3 \mathrm{em}-$ ployees to filter out false or exaggerated claims across 10,000 to 15,000 products per day. In 2019, IBM implemented an intelligent automation process that combined $\mathrm{ML}$ and $\mathrm{AI}$ image and text analysis technologies using RPA to conduct false advertising checks. By implementing RPA, the company could automatically identify exaggerated or false advertising phrases and inappropriate words across the average of 450,000 product technologies registered per month at a shopping mall. In particular, accurate extraction of inappropriate phrases was further improved using optical character recognition, reducing the amount of time spent checking product descriptions by about $70 \%$.

\section{Case B}

Medical Center B in Seoul is a large hospital with 2,700 beds and approximately 700 patients admitted and discharged from 60 medical departments per day. The task of bed assignment was extremely complicated and had a high need for automation. There were approximately 50 criteria for determining bed assignment upon hospitalization, including the relevant medical department, the specific disease, age, gender, urgency, the need for surgery, the need for examination, anesthesia type, patient safety needs, and hospitalization order.

By 2019, the medical center and IBM collaboratively developed an AI-based bed allocation algorithm that used an automated system for 35 clinics across 12 weeks. As a result of the project, in addition to achieving a $0 \%$ error rate, the average time required to confirm an inpatient's medical treatment needs and allocate a bed was reduced by 20 minutes. In addition, more than 100 hospital admissions registration procedures took place every day without the need for human intervention. Factors such as the travel distance of the medical team were reflected in the system, and, as a result, the efficiency of the consultation order was substantially improved.

\section{Case C}

Company $\mathrm{C}$ is one of Korea's largest pharmaceutical companies and invests more than $15 \%$ of its sales in research and development, leading the trend in the Korean pharmaceutical industry. Since the establishment of the Paltan Smart Plant in 2018, various new technologies such as AI and RPA have been introduced to accelerate digital innovation in all fields, including pharmaceutical production, processes, and logistics in 2019.

Previously, management support staff in the finance department had to repeatedly enter all major documents and data manually, which not only decreased accuracy but also process efficiency. IBM implemented intelligent process automation, which incorporates ML and AI image analysis technologies into IBM RPA solutions, to automate key documents and data. Given the automation capabilities of IBM RPA solutions, human-entered critical documents and data can be converted into images, refined, and uploaded as administrative files, improving accuracy and reducing man-hours. As of the time of this study, the company has applied IBM RPA solutions for more than 50 tasks and has eliminated more than 50,000 hours of work and saved more than 1 billion KRW per year.

\section{Case D}

Company $\mathrm{D}$ is the only pharmacovigilance (PV) specialized company in Korea that provides AI and RPA-based PV services. The company in 2021, developed an AI/automation platform to perform adverse case management and medical evaluation more systematically and scientifically. Previously, the PV team conducted over 200 searches in domestic and international journals per week for each active ingredient or product brand name for approximately 100 ingredients/products, taking more than 8 hours according to a preset time limit. These searches 
cover the minimum number of products among more than 400 ethical drug products that required risk monitoring both before and after they are launched on the market. This led to inefficient duplication of business in terms of both manpower and time, making it difficult to confirm high-quality information.

After implementing IBM RPA solutions, the user experience was simplified so that the user could review the list rather than conduct extensive searches to create a list from scratch. By shortening the time required for the literature search, business efficiency improved by 4 to 5 times, with no delays caused by the literature search schedule or omission of products; thus, $100 \%$ compliance was achieved. In addition, as a result of business automation, the manpower previously used to conduct the literature search instead was used to improve the quality of work.

This article briefly sketched several cases in which IBM RPA solutions were implemented in South Korea. We discussed RPA's contributions to business performance and its effects on firms' return on investment. We also found that RPA solutions worked well for AI-based process automation by examining Company A's implementation of a smart inspection process, Company C and Company D's AI-based changes to pharmaceutical and PV processes, and Medical Center B's improved bed assignment algorithm. This article outlined several practical issues when implementing RPA through multiple case studies, including the possible need for change management. We observed the effects of IT investment for firms and showed how RPA can reduce labor costs and increase the operational excellence of firms.

\section{Discussion}

RPA has advantages for businesses in the context of the COVID-19 pandemic, though it is not a new concept. Other concepts similar to RPA include BPM, PI, real-time enterprise, agility management, and process automation. These toolboxes and solutions to enable the acceleration of innovation management for IT vendors have emerged everywhere over recent decades. However, the development of AI has led to the particularly frequent use and diffusion of RPA to improve internal work efficiency. RPA is an excellent tool for innovation and an enabler of digital transformation (Heo \& Lee, 2018). These IT solutions have created many business opportunities for giant vendors of IT solutions, such as IBM, HP, AWS, Bain \& Company, McKinsey \& Company, Samsung SDS, and LG CNS, since IT solutions from these companies have the capability to improve firms' internal efficiency, operational excellence, and performance.
However, there are some practical issues and obstacles concerning the adoption and implementation of RPA. There are various viewpoints concerning RPA-related issues, including among internal organizational members, technical personnel, and clients/customers, as well as new forms of labor. In addition, the costs and benefits of RPA must be examined extensively. To do this, we used the concept of digital shadow work (Ivan, 1981; Lambert, 2015) to examine the customer/client side.

\section{Organizational Members}

The implementation of RPA can internally decrease the intensity of labor related to many types of routine jobs. RPA may act as a smart middleware between firms and customers in the view of bright ICT. However, RPA might also trigger other issues and new types of labor burdens, such as having to accustom business analytics personnel to new processes. Thus, firms should provide skill training on topics such as RPA usage and monitoring or on-the-job training for organizational members and employees regardless of the characteristics of the industry.

\section{Technical and Shadow Work}

RPA requires both employees and customers to have some basic skills. As such, RPA may require some degree of extra effort like digital shadow work (Ryoo \& Park, 2021). Firms should make RPA technically easy to use and helpful. Further, assigning the benefits and costs of RPA to employees and customers might also lead to social welfare issues.

\section{Clients and Customers}

RPA as an attractive toolbox for firms and their members, can increase operational excellence. However, many customers may find it difficult to press multiple keys on their cellphones when interacting with an ARS to contact a firm. This, in turn, could waste time due to the need to connect these customers to call center employees or internal firm members. In particular, in a call center context, customers cannot listen to the voice of machines for insurance contract underwriting for more than 10 minutes. Despite the operational efficiency and cost reduction benefits of firm digitalization and e-transformation, RPA and its peripheral, subsidiary technologies might prove difficult and unpleasant for customers. Even chatbots (Heo \& Lee, 2018), an example of a visual RPA product, may influence customers' emotions and cognitive processes. Therefore, firms should carefully implement RPA in B2C contexts. RPA is, thus, more relevant in $\mathrm{B} 2 \mathrm{~B}$ contexts than $\mathrm{B} 2 \mathrm{C}$ contexts. RPA solution vendors and their client companies should consider digital shadow work issues for digital workers and customers when planning to implement RPA. 
There are some limitations to this study. First, the cases were conveniently selected rather than randomly selected. Moreover, we examined a diverse set of industries to help generalize the findings. However, this limits the ability to focus on specific industries or make comparisons (brick-and-mortar vs. pureclick; financial industry vs. service industry). Second, we only introduced an analytical framework for this case study. A more rigorous study involving multiple cases or a qualitative study using the ground theory method (Strauss \& Corbin, 1998) is needed for future research. Finally, we examined RPA solutions from just one IT solution vendor-IBM Korea-which may hinder the generalizability of the study findings. Despite these limitations, we believe this article can help readers from both academic and business backgrounds understand the state-ofthe-art solutions provided by RPA and their relevance in the context of the COVID-19 pandemic.

\section{Conclusion}

In this article, we examined RPA's implementation in the real world, its contributions to business performance, and its effect on firms. We investigated several practical cases in which RPA was used, created a case report, and discussed the insights from this report. In addition, we examined how RPA can achieve internal operational excellence in a firm. We also discussed several academic and practical implications related to RPA adoption and implementation.

In conclusion, when firms consider adopting and implementing effective solutions like RPA, they must select the processes for which they plan to implement RPA to determine the scope. In addition, they must evaluate the effects of RPA's implementation on performance. Furthermore, firm decision-makers should thoroughly analyze the costs and benefits of RPA for their firms. They should consider the possible downsides, such as unpleasant and mandatory shadow work from the employee and customer perspective. Some employees might resist a new system of automation, which is another hidden cost for change management. Nevertheless, new solutions, which can be well-designed and enabled by robotics or RPA, can have a positive quantitative influence on the performance of many firms. In this study, we shared evidence of several real-world cases in which RPA was introduced. Government officials and policy-makers must design an intricate PI process to balance the advantages and disadvantages of RPA in the public sector.

\section{Acknowledgements}

This work was supported by the Ministry of Education of the
Republic of Korea and the National Research Foundation of Korea (NRF-2021S1A5A2A03064273).

\section{References}

Aguirre, S., \& Rodriguez, A. (2017). Automation of a business process using robotic process automation (RPA): A case study. In J. Figueroa-García, E. López-Santana, J. Villa-Ramírez, \& R. Ferro-Escobar (Eds.), Applied computer sciences in engineering (pp. 65-71). Cham, Switzerland: Springer.

Chang, H., \& Park, M. (2018). A smart e-form for effective business communication in the financial industry. Business Communication Research and Practice, 1(2), 95-101.

Deloitte. (2017). Automate this: The business leader's guide to robotic and intelligent automation. Retrieved from https://www2.deloitte. com/content/dam/Deloitte/us/Documents/process-and-operations/ us-sdt-process-automation.pdf

Heo, M., \& Lee, K. J. (2018). Chatbot as a new business communication tool: The case of Naver TalkTalk. Business Communication Research and Practice, 1(1), 41-45.

Huang, F., \& Vasarhelyi, M. A. (2019). Applying robotic process automation (RPA) in auditing: A framework. International Journal of Accounting Information Systems, 35, 100433.

IEEE Corporate Advisory Group. (2017). IEEE guide for terms and concepts in intelligent process automation. New York, NY: IEEE.

Institute for Robotic Process Automation and Artificial Intelligence [IRPA]. (2016). What is robotic process automation? Retrieved from https://irpaai.com/what-is-robotic-process-automation/ Ivan, I. (1981). Shadow work. Boston, MA: Marion Boyars.

Kwon, T. H., \& Zmud, R. W. (1987). Unifying the fragmented models of information systems implementation. In R. J. Jr., Boland, \& R. A. Hirschheim (Eds.), Critical issues in information systems research (pp. 227-251). New York, NY: John Wiley \& Sons.

Lambert, C. (2015). Shadow work: The unpaid, unseen jobs that fill your day. Berkeley, CA: Counterpoint Press.

Madakam, S., Holmukhe, R. M., \& Jaiswal, D. K. (2019). The future digital work force: Robotic process automation (RPA). Journal of Information Systems and Technology Management, 16, e201916001.

Moffitt, K. C., Rozario, A. M., \& Vasarhelyi, M. A. (2018). Robotic process automation for auditing. Journal of Emerging Technologies in Accounting, 15(1), 1-10.

Park, K., \& Koh, J. (2018). Factors affecting individuals' intentions to discontinue social network services use. Asia Pacific Journal of Information Systems, 28(1), 19-35.

Ryoo, S. Y., \& Park, S. C. (2021). Antecedents and consequences of digital shadow work in mobile shopping apps context. Sustainability, 13(4), 7697.

Son, M., Lee, H., \& Chang, H. (2019). Artificial intelligence-based 
business communication: Application for recruitment and selection. Business Communication Research and Practice, 2(2), 84-92.

Strauss, A., \& Corbin, J. M. (1998). Basics of qualitative research: Techniques and procedures for developing grounded theory (2nd ed.). Los Angeles, CA: Sage.
Thaler, R. H. (1999). Mental accounting matters. Journal of Behavioral Decision Making, 12(3), 183-206.

Willcocks, L. P., Lacity, M., \& Craig, A. (2015, October). The IT function and robotic process automation. Retrieved from http:// eprints.lse.ac.uk/64519/1/OUWRPS_15_05_published.pdf 